\title{
Chronic Obstructive Pulmonary Disease and
}

\section{Incidence of Hip Fracture: A Nested Case-Control Study in the EpiChron Cohort}

This article was published in the following Dove Press journal: International Journal of Chronic Obstructive Pulmonary Disease

\author{
Jesús Díez-Manglano $\mathbb{D}^{1,2}$ \\ María Berges Vidal ${ }^{2}$ \\ Lucía Martínez Barredo 3 \\ Beatriz Poblador-Plou (iD ${ }^{2}$ \\ Antonio Gimeno-Miguel (iD ${ }^{2}$ \\ Pilar Martínez Heras ${ }^{3}$ \\ Alexandra Prados-Torres (iD) ${ }^{2}$ \\ 'Internal Medicine Department, Royo \\ Villanova Hospital, Zaragoza, Spain; \\ ${ }^{2}$ EpiChron Research Group, Aragon \\ Health Sciences Institute, IIS Aragón, \\ REDISSEC, Zaragoza, Spain; ${ }^{3}$ Internal \\ Medicine Department, Miguel Servet \\ University Hospital, Zaragoza, Spain
}

Correspondence: Jesús Díez-Manglano Duquesa Villahermosa $n^{\circ} 163,8^{\circ} \mathrm{D}$,

Zaragoza 50009, Spain

Tel +34976466910

Fax +34976466919

Email jdiez@aragon.es
Purpose: To determine whether chronic obstructive pulmonary disease (COPD) is a risk factor for hip fracture and identify other factors associated with hip fracture.

Patients and Methods: Observational nested case-control study was conducted in Aragon, Spain in 2010. We included COPD patients aged $>40$ years, in the EpiChron cohort. Each COPD patient was matched for age, sex, and number of comorbidities with a control subject without COPD. Patients with an existing diagnosis of osteoporosis and those with hip fracture before 2011 were excluded. We collected baseline demographic, comorbidity, and pharmacological treatment data. During a 5-year follow-up period, we recorded the incidence of hip fracture. A logistic regression model was constructed to identify factors associated with hip fracture.

Results: The study population consisted of 26,517 COPD patients and the same number of controls (median [interquartile range] age, 74 [17] years; women, 24.7\%). Smoking and heart failure were more frequent in COPD patients, and obesity, hypertension, diabetes, dyslipidemia, stroke, arthritis, and visual or hearing impairment were less frequent (all $\mathrm{p}<0.001$ ). Consumption of benzodiazepines $(\mathrm{p}=0.037)$, bronchodilators $(\mathrm{p}<0.001)$, and corticosteroids $(\mathrm{p}<0.001)$ was higher in the COPD group, while that of beta-blockers and thiazides was lower (both $\mathrm{p}<0.001)$. During follow-up, 898 (1.7\%) patients experienced hip fracture, with no differences observed between COPD and control patients. Multivariate analysis revealed that independent of COPD status, age, female sex, chronic liver disease, heart failure, and benzodiazepine use were independently associated with a higher risk of hip fracture, and obesity with a lower risk. In COPD patients, use of inhaled anticholinergics was independently associated with hip fracture (OR, 1.390; 95\% CI 1.134-1.702; $\mathrm{p}=0.001$ ).

Conclusion: COPD is not a risk factor for a hip fracture within 5 years. The association between the use of inhaled anticholinergics and risk of hip fracture warrants further study.

Keywords: chronic obstructive pulmonary disease, hip fracture, case-control study, incidence

\section{Introduction}

The world population is aging. Recent years have seen an increase in life expectancy in Spain and in the rest of the world. According to the World Health Organization, between 2015 and 2050 the proportion of the population aged 60 years and over will increase from $12 \%$ to $22 \%$ worldwide, an increase of 1.1 billion. $^{1}$

Hip fracture is an age-associated health problem that frequently causes disability and worsening quality of life, leading to high healthcare costs and high mortality. ${ }^{2}$ Frailty and osteoporosis are known causes of hip fracture. ${ }^{3}$ 
Chronic obstructive pulmonary disease (COPD) constitutes a public health problem owing to its high prevalence, morbidity, and mortality. The World Health Organization estimates that by 2030 COPD will become the third cause of death globally. ${ }^{4}$ In addition to affecting the airways, COPD also has extrapulmonary effects. Malnutrition, falls, and osteoporosis, all of which are also associated with hip fracture, are more frequent in COPD patients. ${ }^{5-7}$

Some studies have reported a decrease in bone mass in COPD patients. ${ }^{8}$ Using the FRAX tool, a study of COPD patients hospitalized for exacerbation found that half of all patients were at high risk of hip fracture within 10 years. ${ }^{9}$

The objective of this study was to determine the incidence of hip fracture in COPD patients and to identify possible factors related to its occurrence.

\section{Patients and Methods Design}

We conducted an observational nested case-control study in the EpiChron cohort in 2010. The cohort, which has been previously described, ${ }^{10}$ consisted of anonymous demographic, clinical, and drug dispensing data from all users of the public health system of Aragon, Spain. The Spanish national health system provides free healthcare with universal coverage to approximately $95 \%$ of the population in Aragon.

\section{Participants}

We included the individuals $>40$ years old in the EpiChron cohort with a diagnosis of COPD recorded in their primary healthcare and/or hospital electronic records. Patients with a previous diagnosis of osteoporosis and those who had experienced hip fracture before 2010 were excluded. For each case, we selected a COPD-free control matched for age, sex, and number of comorbidities.

For each patient, the following variables were collected: age, sex, smoking status, alcohol consumption, diagnosed chronic diseases, and prescribed drugs. Disease diagnoses recorded in primary care and hospital electronic health records were coded according to the International Classification of Primary Care (ICPC) and the International Classification of Diseases, 9th Revision (ICD-9), respectively. Prescribed drugs were classified according to the third level of the Anatomical Therapeutic Chemical (ATC) Classification System (ie, by pharmacological subgroup).

Participants were followed for 5 years (until December 31, 2015), or until death or removal from the database of health system users. The incidence of hip fracture, as defined by ICD-9 codes $820.0-820.9,{ }^{11}$ was recorded during the follow-up period.

The study was approved by the Clinical Research Ethics Committee of Aragón (PI 18/131) and carried out in accordance with the principles of the Declaration of Helsinki and Spain's Organic Law for the Protection of Personal Data. The ethics committee waived the requirement for informed consent given the epidemiological nature of the project, which used anonymized data and did not involve any type of intervention.

\section{Statistical Analysis}

We described the baseline demographic and clinical characteristics of the study population based on the presence or absence of COPD. Qualitative variables were expressed as frequencies or percentages and quantitative variables as the median and interquartile range. Qualitative variables were compared using the Chi-squared test and quantitative variables using the Mann Whitney $U$-test.

To study the factors associated with the incidence of hip fracture, we performed a logistic regression model with the enter method, using in the multivariate model those variables associated with p-value $<0.1$ in the univariate model. We constructed Kaplan-Meier curves to analyze the incidence of hip fracture and compared them using the Log rank test.

In every case, we established the level of statistical significance for a value of $\mathrm{p}<0.05$. We used the Statistical Package for the Social Sciences (SPSS; version 21.0 for Windows) for all statistical analyses.

\section{Results}

Figure 1 shows the flowchart of included patients. In December 2010, the EpiChron cohort consisted of 1,314,450 subjects and 577,934 had no exclusion criteria. Of them, 26,517 had a diagnosis of COPD.

\section{Patient Characteristics}

The baseline characteristics of subjects with and without COPD are presented in Table 1. The median [interquartile range] age was 74 [17] years, and $24.7 \%$ of the study population were women. The prevalence of smoking and heart failure was higher in the COPD group (20.4\% vs $11.8 \%$, p $<0.001$, and $18.3 \%$ vs $13.0 \%, \mathrm{p}<0.001$, respectively), while that of obesity $(18.3 \%$ vs $21.1 \%)$, high blood pressure $(61.4 \%$ vs $70.4 \%$ ), diabetes $(27.0 \%$ vs $33.9 \%)$, dyslipidemia ( $43.8 \%$ vs $54.2 \%$ ), stroke ( $14.5 \%$ vs $18.0 \%)$, arthritis ( $25.8 \%$ vs $32.8 \%$ ), 


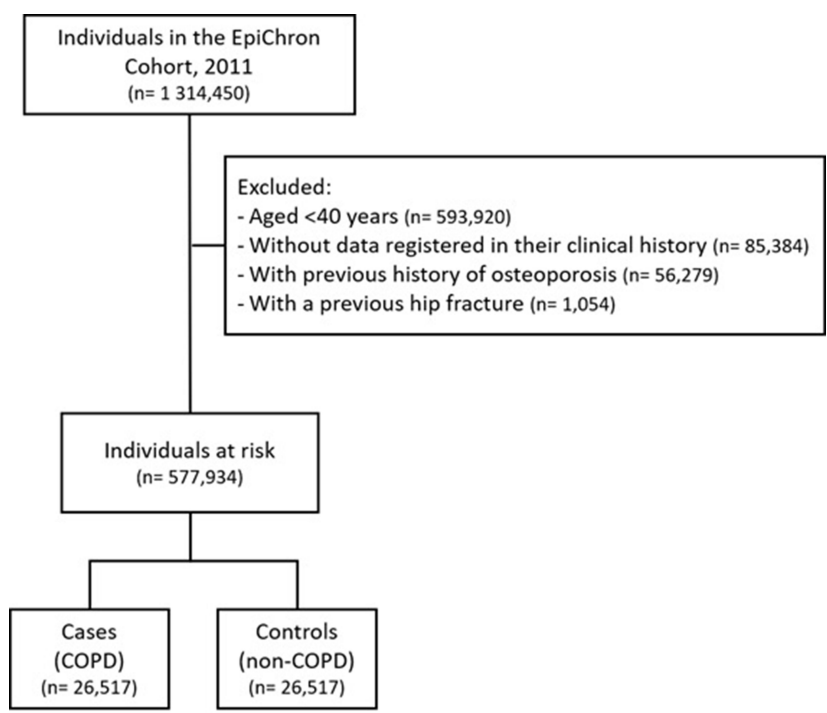

Figure I Flowchart of patients included in the study.

and visual $(8.6 \%$ vs $10.0 \%)$ or hearing impairment (13.0\% vs $15.5 \%$ ) was lower (all $\mathrm{p}<0.001$ ). Consumption of benzodiazepines $(23.2 \%$ vs $22.4 \%$; $\mathrm{p}=0.037)$, bronchodilators, and corticosteroids (both $\mathrm{p}<0.001$ ) was higher in the COPD group, while that of beta-blockers and thiazides was lower (both $\mathrm{p}<0.001)$.

\section{Incidence of Hip Fracture}

During the 5-year follow-up period, 898 (1.7\%) patients experienced hip fracture, with no evident differences in incidence between the COPD and the control group (Figure 2). Table 2 shows the differences between patients with and without hip fracture in COPD and control groups. There was no association between COPD and hip fracture (OR 1.042, 95\% CI 0.913-1.189) even when we adjusted the model for age, sex, systemic corticosteroids, obesity, hypertension, hyperlipidemia, arthritis, heart failure, stroke, chronic liver disease, smoking, alcoholism, use of benzodiazepines, inhaled anticholinergics agents and calcium (OR 0.975, 95\% CI 0.843-1.128). Multivariate analysis revealed that independent of COPD status, age, female sex, chronic liver disease, heart failure, and benzodiazepine use were independently associated with a higher risk of hip fracture, and obesity with a lower risk. Hyperlipidemia and stroke were associated with hip fracture in patients without COPD. The use of inhaled anticholinergics was independently associated with hip fracture in COPD patients (OR, 1.390; 95\% CI 1.134-1.702; $\mathrm{p}=0.001)($ Table 3$)$.
Table I Baseline Characteristics of the Study Population with and without Chronic Obstructive Pulmonary Disease (COPD)

\begin{tabular}{|c|c|c|c|}
\hline Characteristics & $\begin{array}{l}\text { With } \\
\text { COPD (N= } \\
26,517)\end{array}$ & $\begin{array}{l}\text { Without } \\
\text { COPD (N= } \\
26,517)\end{array}$ & $P$ value \\
\hline \multicolumn{4}{|l|}{$\begin{array}{l}\text { Demographic and lifestyle } \\
(n, \%)\end{array}$} \\
\hline Women & 6551 (24.7) & 6551 (24.7) & 1.000 \\
\hline Age (Median, IQR) & $74(17)$ & $74(17)$ & 1.000 \\
\hline $\begin{array}{l}\text { Body mass index (Median, } \\
\text { IQR) }\end{array}$ & $29.0(6.4)$ & $29.2(5.8)$ & $<0.001$ \\
\hline Active smoking & $5399(20.4)$ & $3131(11.8)$ & $<0.001$ \\
\hline Alcoholism & $5883(22.2)$ & $6026(22.7)$ & 0.139 \\
\hline \multicolumn{4}{|l|}{ Comorbidities (n, \%) } \\
\hline Number (Median, IQR) & $4(5)$ & $5(5)$ & $<0.001$ \\
\hline Obesity & $4854(18.3)$ & $5577(21.1)$ & $<0.001$ \\
\hline Hypertension & $16,264(61.4)$ & $18,648(70.4)$ & $<0.001$ \\
\hline Diabetes & 7161 (27.0) & 8972 (33.9) & $<0.001$ \\
\hline Hyperlipidemia & II,603 (43.8) & I4,358 (54.2) & $<0.001$ \\
\hline Chronic liver disease & $579(2.2)$ & $555(2.1)$ & 0.488 \\
\hline Heart failure & $4849(18.3)$ & $3432(13.0)$ & $<0.001$ \\
\hline Stroke & $3831(14.5)$ & $4763(18.0)$ & $<0.001$ \\
\hline Arthritis & $6823(25.8)$ & $8676(32.8)$ & $<0.001$ \\
\hline Visual impairment & $2278(8.6)$ & $2645(10.0)$ & $<0.001$ \\
\hline Hearing impairment & $3437(13.0)$ & $4100(15.5)$ & $<0.001$ \\
\hline \multicolumn{4}{|l|}{ Prescribed drugs (n, \%) } \\
\hline Benzodiazepines & $6151(23.2)$ & $5948(22.4)$ & 0.037 \\
\hline Systemic corticosteroids & $2044(7.7)$ & $1075(4.1)$ & $<0.001$ \\
\hline $\begin{array}{l}\text { Inhaled beta adrenergics, } \\
\text { plain }\end{array}$ & $3676(13.9)$ & $450(1.7)$ & $<0.001$ \\
\hline $\begin{array}{l}\text { Inhaled beta adrenergics, } \\
\text { double therapy }\end{array}$ & $7363(27.8)$ & 991 (3.7) & $<0.001$ \\
\hline Inhaled glucocorticoids & $972(3.7)$ & $143(0.5)$ & $<0.001$ \\
\hline Inhaled anticholinergics & $7589(28.6)$ & $788(3.0)$ & $<0.001$ \\
\hline Inhaled antiallergic agents & I (0.0) & $0(0.0)$ & 1.000 \\
\hline Systemic adrenergics, plain & $22(0.1)$ & $8(0.0)$ & 0.018 \\
\hline Beta-blockers & $2927(11.0)$ & 4744 (17.9) & $<0.001$ \\
\hline Thiazides & $234(0.9)$ & $316(1.2)$ & $<0.001$ \\
\hline $\begin{array}{l}\text { Nonsteroidal anti- } \\
\text { inflammatory drugs }\end{array}$ & $3254(12.3)$ & $3351(12.6)$ & 0.207 \\
\hline Androgens & $15(0.1)$ & $31(0.1)$ & 0.027 \\
\hline Estrogens & $6(0.0)$ & $14(0.1)$ & 0.117 \\
\hline Calcium & $637(2.4)$ & $632(2.4)$ & 0.910 \\
\hline Vitamin D & $301(1.1)$ & $321(1.2)$ & 0.443 \\
\hline Bisphosphonates & $288(I .1)$ & $250(0.9)$ & 0.109 \\
\hline
\end{tabular}

\section{Discussion}

COPD is a poor prognostic factor in patients with hip fracture. Studies using databases in Japan, Denmark, the United Kingdom, and the United States have found that COPD is associated with higher mortality in the short and medium term in patients with hip fracture. ${ }^{12-16}$ Moreover, COPD patients more frequently develop surgical wound 


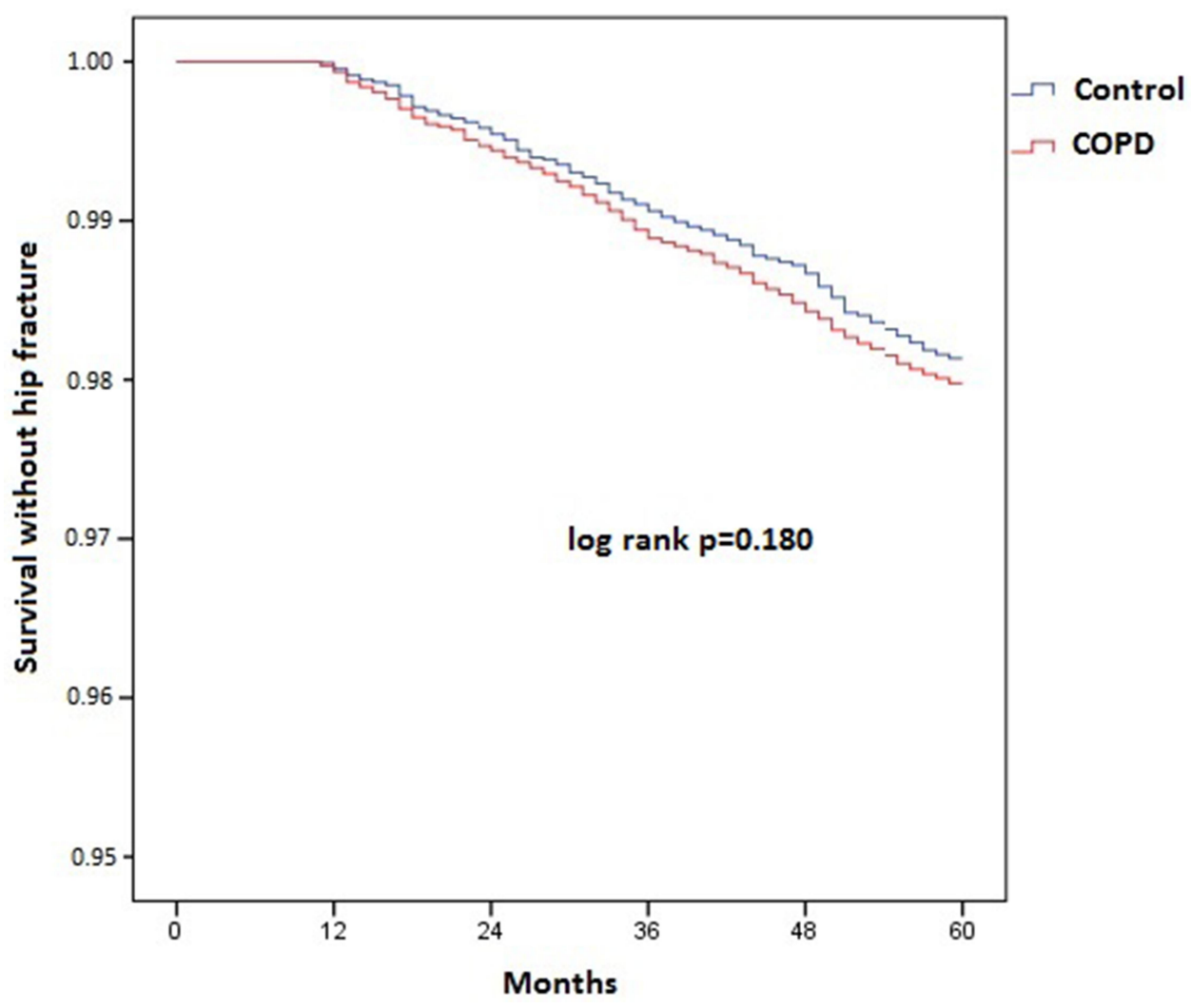

Figure 2 Kaplan-Meier curves of incidence of hip fracture.

infections, respiratory infections, and sepsis, have longer hospital stays and require more time for rehabilitation. ${ }^{15-17}$

Osteoporosis is an important comorbidity of COPD. It is frequently undiagnosed and is associated with poorer health and a poor prognosis. ${ }^{18,19}$ Patients with both COPD and osteoporosis have more exacerbations and more hospitalizations. ${ }^{20}$ Furthermore, a higher rate of COPD exacerbations has been associated with an increased risk of osteoporosis and a greater decrease in bone mass. ${ }^{21,22}$ A cross-sectional study conducted in Spain measured the risk of hip fracture within the following ten years using the FRAX tool, and observed that half of all patients hospitalized for COPD had a high risk $(>3 \%) .{ }^{9}$ In a UK study, $40 \%$ of COPD patients in primary care were deemed highrisk based on FRAX score, and $45.6 \%$ based on the QFracture score. ${ }^{23}$ Another UK study using the FRAX tool reported a high risk of hip fracture in outpatients with severe COPD. ${ }^{24}$ In line with these findings, a recent study identified COPD as a risk factor for hip fracture. ${ }^{25}$

A retrospective observational study by Miguel et al selected patients hospitalized for hip fracture using the Spanish Minimum Basic Data Set and found that the incidence of hip fracture was higher in patients with
COPD.${ }^{26}$ However, in this study, the incidence rates were calculated indirectly extrapolating data from other studies. Another Spanish population cohort study reported that of the comorbidities included in the Charlson index, COPD was associated with the occurrence of hip fracture in men with a relative risk of $1.20(95 \%$ CI $1.03-1.40) .{ }^{27}$ A retrospective case-control study of Taiwanese COPD patients found that the hazard ratio for hip fracture within two years was $1.57 .^{28}$ In the Norwegian Hordaland Health Study, in which the general population was followed for ten years, COPD was associated with a higher incidence of hip fracture, ${ }^{8}$ and a greater degree of airway obstruction was associated with increased risk of hip fracture.

In contrast to previous studies, we did not observe an excess risk of hip fracture among COPD patients. Using an approach similar to ours, Akyea et al analyzed electronic health records and observed an increased risk of hip fracture among COPD patients, although this increase was not observed after adjusting for age, sex, Charlson index, body mass index, and the use of inhaled corticosteroids. ${ }^{23}$ In our study, we matched patients by age, sex, and number of comorbidities. In the Hordaland Health Study, patients with COPD were significantly 
Table 2 Characteristics of COPD Patients and Controls with and without Hip Fracture

\begin{tabular}{|c|c|c|c|c|c|c|}
\hline \multirow[t]{2}{*}{ Characteristics } & \multicolumn{3}{|c|}{ COPD Patients } & \multicolumn{3}{|l|}{ Controls } \\
\hline & $\begin{array}{l}\text { With HF } \\
(n=458)\end{array}$ & $\begin{array}{l}\text { Without HF } \\
(n=26,059)\end{array}$ & $P$ value & $\begin{array}{l}\text { With HF } \\
(n=440)\end{array}$ & $\begin{array}{l}\text { Without HF } \\
(n=26,077)\end{array}$ & $P$ value \\
\hline \multicolumn{7}{|l|}{ Demographic and lifestyle (n, \%) } \\
\hline Women & $183(40.0)$ & $6368(24.4)$ & $<0.001$ & $165(37.5)$ & $6386(24.5)$ & $<0.001$ \\
\hline Age (Median, IQR) & $83(10)$ & $74(17)$ & $<0.001$ & $83(10)$ & $74(17)$ & $<0.001$ \\
\hline Body mass index (Median, IQR) & $27.5(5.7)$ & $29.0(6.4)$ & $<0.001$ & $27.2(5.7)$ & $29.2(5.8)$ & $<0.001$ \\
\hline Active smoking & $42(9.2)$ & $5357(20.6)$ & $<0.001$ & $18(4.1)$ & $3113(11.9)$ & $<0.001$ \\
\hline Alcoholism & $47(10.3)$ & $5836(22.4)$ & $<0.001$ & 49 (II.I) & $5977(22.9)$ & $<0.001$ \\
\hline \multicolumn{7}{|l|}{ Comorbidities (n, \%) } \\
\hline Number (Median, IQR) & $5(5)$ & $4(5)$ & $<0.001$ & $7(5)$ & $5(5)$ & $<0.001$ \\
\hline Obesity & $59(12.9)$ & $4795(18.4)$ & 0.003 & $51(11.6)$ & $5526(21.2)$ & $<0.001$ \\
\hline Hypertension & $350(76.4)$ & $15,9 \mid 4(6||)$. & $<0.001$ & $358(81.4)$ & $18,290(70.2)$ & $<0.001$ \\
\hline Diabetes & $138(30.1)$ & $7023(27.0)$ & 0.147 & $170(38.6)$ & $8802(33.8)$ & 0.038 \\
\hline Hyperlipidemia & $163(35.6)$ & II,440 (44.0) & $<0.001$ & $\mid 84(4 \mid .8)$ & $14,174(54.4)$ & $<0.001$ \\
\hline Chronic liver disease & $17(3.7)$ & $562(2.2)$ & 0.037 & $17(3.9)$ & $538(2.1)$ & 0.015 \\
\hline Heart failure & 169 (36.9) & $4680(18.0)$ & $<0.001$ & $|2|(27.5)$ & $3311(12.7)$ & $<0.001$ \\
\hline Stroke & $108(23.6)$ & $3723(14.3)$ & $<0.001$ & $157(35.7)$ & $4606(17.7)$ & $<0.001$ \\
\hline Arthritis & $145(3 \mid .7)$ & $6678(25.7)$ & 0.004 & $167(38.0)$ & 8509 (32.7) & 0.022 \\
\hline Visual impairment & $46(10.0)$ & $2232(8.6)$ & 0.305 & $39(8.9)$ & $2606(10.0)$ & 0.477 \\
\hline Hearing impairment & 73 (I5.9) & 3364 (12.9) & 0.067 & 70 (I5.9) & $4030(15.5)$ & 0.853 \\
\hline \multicolumn{7}{|l|}{ Prescribed drugs (n, \%) } \\
\hline Benzodiazepines & $15 \mid(33.0)$ & $6000(23.0)$ & $<0.001$ & $132(30.0)$ & $5816(22.3)$ & $<0.001$ \\
\hline Systemic corticosteroids & $40(8.7)$ & $2004(7.7)$ & 0.458 & $15(3.4)$ & $1060(4.1)$ & 0.569 \\
\hline Inhaled beta adrenergics, plain & $65(14.2)$ & $3611(13.9)$ & 0.891 & $9(2.0)$ & $44 \mid(1.7)$ & 0.701 \\
\hline Inhaled beta adrenergics, double therapy & $132(28.8)$ & 7231 (27.7) & 0.649 & $20(4.5)$ & 971 (3.7) & 0.439 \\
\hline Inhaled glucocorticoids & $20(4.4)$ & $952(3.7)$ & 0.496 & $2(0.5)$ & $|4|(0.5)$ & 1.000 \\
\hline Inhaled anticholinergics & $156(34.1)$ & $7433(28.1)$ & 0.011 & $13(3.0)$ & $775(3.0)$ & 1.000 \\
\hline Inhaled antiallergic agents & $0(0.0)$ & $\mathrm{I}(0.0)$ & 1.000 & $0(0.0)$ & $0(0.0)$ & 1.000 \\
\hline Systemic adrenergics, plain & $0(0.0)$ & $22(0.1)$ & 1.000 & $\mathrm{I}(0.2)$ & $7(0.0)$ & 0.125 \\
\hline Beta-blockers & $44(9.6)$ & $2883(11.1)$ & 0.362 & $86(19.5)$ & $4658(17.9)$ & 0.395 \\
\hline Thiazides & $5(I . I)$ & $229(0.9)$ & 0.817 & $2(0.5)$ & $314(1.2)$ & 0.224 \\
\hline Nonsteroidal anti-inflammatory drugs & $61(13.3)$ & $3193(12.3)$ & 0.537 & $52(11.8)$ & $3299(12.7)$ & 0.653 \\
\hline Androgens & $0(0.0)$ & $15(0.1)$ & 1.000 & $0(0.0)$ & $31(0.1)$ & 1.000 \\
\hline Estrogens & $0(0.0)$ & $6(0.0)$ & 1.000 & $0(0.0)$ & $14(0.1)$ & 1.000 \\
\hline Calcium & $20(4.4)$ & $617(2.4)$ & 0.009 & $14(3.2)$ & $618(2.4)$ & 0.342 \\
\hline Vitamin D & $3(0.7)$ & $298(1.1)$ & 0.450 & $4(0.9)$ & $317(1.2)$ & 0.716 \\
\hline Bisphosphonates & $8(1.7)$ & $280(1.1)$ & 0.251 & $10(2.3)$ & $240(0.9)$ & 0.009 \\
\hline
\end{tabular}

older than those without, which may explain the higher incidence of hip fracture in this group. ${ }^{8}$ In the study by de Miguel et al, although the age of the study groups was similar, comorbidity was greater among COPD patients. ${ }^{26}$ Huang et al reported a higher risk of hip fracture among patients with COPD than those without, even after adjusting for age, sex, and comorbidities. ${ }^{28}$ Furthermore, those authors used a follow-up period of 4 years; 1 year less than that used in the present study. Based on the present findings and those reported to date, the relationship between COPD and hip fracture therefore remains unclear.

Several factors may explain the higher incidence of hip fractures among COPD patients. On the one hand, patients with poorer lung function tend to show a greater decrease in bone mass, ${ }^{29}$ and on the other hand, patients with COPD experience more falls than those without. ${ }^{7}$ Finally, patients with frequent COPD exacerbations are intermittently treated with high doses of systemic corticosteroids that can contribute to the appearance of fractures. ${ }^{30}$ 
Table 3 Factors Independently Associated with Hip Fracture in the Multivariate Analysis of Individuals with and without Chronic Obstructive Pulmonary Disease (COPD)

\begin{tabular}{|c|c|c|}
\hline \multicolumn{3}{|l|}{ Individuals with COPD } \\
\hline & OR (95\% Cl) & $\mathrm{p}$ value \\
\hline Age & $1.09(1.08-1.10)$ & $<0.001$ \\
\hline Sex, women & $1.73(1.4 \mathrm{I}-2.12)$ & $<0.001$ \\
\hline Obesity & $0.75(0.56-0.99)$ & 0.045 \\
\hline Hypertension & $1.45(1.16-1.83)$ & 0.001 \\
\hline Heart failure & $1.36(1.10-1.68)$ & 0.005 \\
\hline Chronic liver disease & $2.62(1.58-4.37)$ & $<0.001$ \\
\hline Benzodiazepines & $1.45(1.19-1.78)$ & $<0.001$ \\
\hline Inhaled anticholinergics & $1.39(1.13-1.70)$ & 0.001 \\
\hline \multicolumn{3}{|c|}{ Individuals without COPD } \\
\hline & OR (95\% Cl) & $\mathrm{p}$ value \\
\hline Age & $1.08(1.07-1.09)$ & $<0.001$ \\
\hline Sex, women & $1.59(1.28-1.96)$ & $<0.001$ \\
\hline Obesity & $0.57(0.42-0.78)$ & $<0.001$ \\
\hline Hyperlipidemia & $0.79(0.64-0.96)$ & 0.019 \\
\hline Heart failure & $1.28(1.01-1.61)$ & 0.040 \\
\hline Stroke & $1.50(1.22-1.85)$ & $<0.001$ \\
\hline Chronic liver disease & $2.42(1.45-4.02)$ & 0.001 \\
\hline Benzodiazepines & $1.31(1.06-1.61)$ & 0.014 \\
\hline
\end{tabular}

Abbreviations: $\mathrm{Cl}$, confidence interval; $\mathrm{OR}$, odds ratio.

One surprising finding in our study was the association between hip fracture and treatment with anticholinergic bronchodilators in COPD patients. As early as 2011, Morden et al, in their analysis of data from the Veterans Administration database, reported that the use of inhaled corticosteroids was associated with hip and wrist fractures in men aged over 50 years who were newly diagnosed with COPD. ${ }^{31}$ More recent studies reported only a modest increase in the risk of fracture, and only in patients receiving high doses of inhaled corticosteroids. $^{32,33}$ Inhaled beta-agonists, especially when administered at high doses, have also been associated with femur fractures in COPD patients. ${ }^{34,35}$ To our knowledge, ours is the first study to report an association between antimuscarinics and the incidence of hip fracture. Given the frequency of osteoporosis and fractures in COPD patients, all pharmacovigilance studies with new bronchodilators should include fractures as an adverse effect to be monitored.

The findings of this study are strengthened by the use of a population database that includes a large number of comorbidities and medications. Nonetheless, several study limitations should be noted. First, we excluded patients with previously diagnosed osteoporosis and those that had previously experienced hip fracture. It is possible that
COPD causes greater exacerbation of pre-existing osteoporosis in these particular patients, increasing the likelihood of new fractures, and that these patients were not accounted for in our analysis. Second, while studies using the FRAX tool have established that COPD patients are at high risk of hip fracture within ten years, the follow-up period in the present study was only five years. It is possible that hip fractures occur more frequently between five and ten years, and that our follow-up period was not sufficiently long to detect such fractures. In fact, the mean age of patients with hip fracture in Spain is 86.7 years, twelve years higher than in our patients. ${ }^{36}$

In conclusion, in our study population, COPD was not a risk factor for hip fracture within the next five years. However, studies with a longer follow-up period will be necessary to clarify any potential association. The possible association between treatment with inhaled anticholinergics and hip fracture should be monitored and further researched in patients with COPD.

\section{Funding}

This study was funded by Gobierno de Aragón and the European Regional Development Fund "Construyendo Europa desde Aragón” gran number B01_20R. Funders had no role in study design or in the decision to submit the report for publication.

\section{Disclosure}

Jesús Díez-Manglano reports grants from Fondo de Investigaciones Sanitarias ISCIII, REDISSEC, and European Regional Development Fund, during the conduct of the study. The authors report no other potential conflicts of interest for this work.

\section{References}

1. World Health Organization. 10 facts on ageing and health. Available from: https://www.who.int/features/factfiles/ageing/en/. Accessed July 01, 2020.

2. Veronese N, Maggi S. Epidemiology and social costs of hip fracture. Injury. 2018;49:1458-1460. doi:10.1016/j.injury.2018.04.015

3. Rolland Y, Abellan van Kan G, Benetos A, et al. Frailty, osteoporosis and hip fracture: causes, consequences and therapeutic perspectives. J Nutr Health Aging. 2008;12:335-346.

4. World Health Organization. Chronic obstructive pulmonary disease (COPD). Available from: https://www.who.int/respiratory/copd/en/. Accessed July 01, 2020.

5. De Blasio F, Di Gregorio A, De Blasio F, Bianco A, Bellofiore B, Scalfi L. Malnutrition and sarcopenia assessment in patients with chronic obstructive pulmonary disease according to international diagnostic criteria, and evaluation of raw BIA variables. Respir Med. 2018;134:1-5. doi:10.1016/j.rmed.2017.11.006 
6. Chen YW, Ramsook AH, Coxson HO, Bon J, Reid WD. Prevalence and risk factors for osteoporosis in individuals with COPD: a systematic review and meta-analysis. Chest. 2019;156:1092-1110. doi:10.1016/j.chest.2019.06.036

7. Hakamy A, Bolton CE, Gibson JE, McKeever TM. Risk of fall in patients with COPD. Thorax. 2018;73:1079-1081. doi:10.1136/thoraxjnl-2017-211008

8. Herland T, Apalset EM, Eide GE, Tell GS, Lehmann S. Airflow limitation as a risk factor for low bone mineral density and hip fracture The Hordaland Health Study (HUSK) _ 10 years follow-up of a general population. Eur Clin Respir J. 2016;3:32214. doi:10.3402/ecrj.v3.32214

9. Díez-Manglano J, López-García F, Barquero-Romero J, et al. Riesgo de fractura osteoporótica y de cadera en pacientes con enfermedad pulmonar obstructiva crónica. Rev Clin Esp. 2011;211:443-449. doi:10.1016/j.rce.2011.04.010

10. Prados-Torres A, Poblador-Plou B, Gimeno-Miguel A, et al. Cohort profile: the epidemiology of chronic diseases and multimorbidity. The EpiChron Cohort Study. Int $J$ Epidemiol. 2018;47:382-384. doi:10.1093/ije/dyx259

11. Complete ICD-9 manual. Available from: ftp://ftp.cdc.gov/pub/ Health_Statistics/NCHS/Publications/ICD-9/ucod.txt. Accessed July 01, 2020.

12. Yamauchi Y, Yasunaga H, Sakamoto Y, et al. Mortality associated with bone fractures in COPD patients. Int J Chron Obstruct Pulmon Dis. 2016;11:2335-2340. doi:10.2147/COPD.S112142

13. De Luise B, Brimacombe M, Pedersen L, Sorensen HT. Chronic obstructive pulmonary disease and mortality following hip fracture: a population-based cohort study. Eur J Epidemiol. 2008;23:115-122. doi:10.1007/s10654-007-9211-5

14. Dodd AC, Bulka C, Jahangir A, Mir HR, Obremskey WT, Sethi MK. Predictors of 30-day mortality following hip/pelvis fractures. Orthop Traumatol Surg Res. 2016;102:707-710. doi:10.1016/j. otsr.2016.05.016

15. Buss L, McKeever TM, Nightingale J, et al. Hip fracture outcomes in patients with chronic obstructive pulmonary disease. $\mathrm{Br} J$ Anaesth 2018;121:1377-1379. doi:10.1016/j.bja.2018.09.008

16. Regan EA, Radcliff TA, Henderson WG, et al. Improving hip fractures outcomes for COPD patients. COPD. 2013;10:11-19. doi:10.3109/15412555.2012.723072

17. Smrke D, Biscevic M, Rejec B, Smajic S. [Verlängerte Rehabilitationsdauer bei Patienten mit chronischen Lungenerkrankungen nach Schenkelhalsfrakturen]. Z Orthop Unfall. 2009;147:32-36.

18. Global Initiative for Chronic Obstructive Lung Disease. Global strategy for diagnosis, management, and prevention of chronic obstructive pulmonary disease. 2020 report. Available from: https://goldcopd.org/ gold-reports/. Accessed July 01, 2020.

19. Graat-Verboom L, Spruit MA, Van Den Borne BE, et al. Correlates of osteoporosis in chronic obstructive pulmonary disease: an underestimated systemic component. Respir Med. 2009;103:1143-1151. doi:10.1016/j.rmed.2009.02.014

20. Romme EA, Murchison JT, Edwards LD, et al. CT measured bone attenuation in patients with chronic obstructive pulmonary disease: relation to clinical features and outcomes. $J$ Bone Miner Res. 2013;28:1369-1377. doi:10.1002/jbmr.1873

21. Hattiholi J, Gaude GS. Prevalence and correlates of osteoporosis in chronic obstructive pulmonary disease patients in India. Lung India. 2014;31:221-227. doi:10.4103/0970-2113.135759
22. Kiyokawa H, Muro S, Oguma T, et al. Impact of COPD exacerbations on osteoporosis assessed by chest CT scan. COPD. 2012;9:235-242. doi:10.3109/15412555.2011.650243

23. Akyea RK, McKeever TM, Gibson J, Scullion JE, Bolton CE. Predicting fracture risk in patients with chronic obstructive pulmonary disease: a UK-based population-based cohort study. BMJ Open. 2019;9:e024951. doi:10.1136/bmjopen-2018-024951

24. Gupta A, Greening NJ, Evans RA, Samuels A, Toms N, Stenier M. Prospective risk of osteoporotic fractures in patients with advanced chronic obstructive pulmonary disease. Chron Respir Dis. 2018;16:1-8.

25. Liao KM, Liang FW, Li CY. Risks of all-cause and site-specific fractures among hospitalized patients with COPD. Medicine (Baltimore). 2016;95:e5070. doi:10.1097/MD.0000000000005070

26. De Miguel-diez J, Jimenez-Garcia R, Hernande-Barrera V, et al. Is COPD a risk factor for hip fracture? COPD. 2016;13:779-789. doi:10.1080/15412555.2016.1195348

27. Reyes C, Estrada P, Nogués X, et al. The impact of common co-morbidities (as measured using the Charlson index) on hip fracture risk in elderly men: a population-based cohort study. Osteoporos Int. 2014;25:1751-1758.

28. Huang SW, Wang WT, Chou LC, Chen HC, Liou TH, Lin HW. Chronic obstructive pulmonary disease increases the risk of hip fracture: A nationwide population-based cohort study. Sci Rep. 2016;6:23360. doi:10.1038/srep23360

29. Zheng X, Liu D, Zhao X, et al. Association of bone mineral density with lung function in a Chinese general population: the Xinxiang rural cohort study. BMC Pulm Med. 2019;19:239. doi:10.1186/ s12890-019-1008-2

30. Oshagbemi OA, Burden AM, Shudofsky KN, et al. Use of high-dose intermittent systemic glucocorticoids and the risk of fracture in patients with chronic obstructive pulmonary disease. Bone. 2018;110:238-243. doi:10.1016/j.bone.2018.02.007

31. Morden NE, Sullivan SD, Bartle B, Lee TA. Skeletal health in men with chronic lung disease: rates of testing, treatment, and fractures. Osteoporos Int. 2011;22:1855-1862. doi:10.1007/s00198-010-1423-y

32. Gonzalez AV, Coulombe J, Ernst P, Suissa S. Long-term use of inhaled corticosteroids in COPD and the risk of fracture. Chest. 2018;153:321-328. doi:10.1016/j.chest.2017.07.002

33. Tsai CH, Liao LY, Lin CL, Chung WS. Inhaled corticosteroids and the risks of low-energy fractures in patients with chronic airway diseases: A propensity score matched study. Clin Respir J. 2018;12:1830-1837.

34. De Vries F, Powels S, Bracke M, et al. Use of beta-2 agonists and risk of hip/femur fracture: a population-based case-control study. Pharmacoepidemiol Drug Saf. 2007;16:612-619. doi:10.1002/ pds. 1318

35. Vestergaard P, Renjmark L, Mosekilde L. Fracture risk in patients with chronic lung diseases treated with bronchodilator drugs and inhaled and oral corticosteroids. Chest. 2007;132:1599-1607. doi:10.1378/chest.07-1092

36. Ojeda-Thies C, Sáez-López P, Currie CT, et al. Spanish National Hip Fracture Registry (RNFC): analysis of its first annual report and international comparison with other established registries. Osteoporos Int. 2019;30:1243-1254. doi:10.1007/s00198-01904939-2 


\section{Publish your work in this journal}

The International Journal of COPD is an international, peer-reviewed journal of therapeutics and pharmacology focusing on concise rapid reporting of clinical studies and reviews in COPD. Special focus is given to the pathophysiological processes underlying the disease, intervention programs, patient focused education, and self management protocols. This journal is indexed on PubMed Central, MedLine and CAS. The manuscript management system is completely online and includes a very quick and fair peer-review system, which is all easy to use. Visit http://www.dovepress.com/testimonials.php to read real quotes from published authors.

Submit your manuscript here: https://www.dovepress.com/international-journal-of-chronic-obstructive-pulmonary-disease-journal 